\title{
Epidemiological study of vibration syndrome in response to total hand-tool operating time
}

\author{
K MIYASHITA, S SHIOMI, N ITOH, T KASAMATSU, AND H IWATA \\ From the Department of Public Health, Wakayama Medical College, Wakayama, 640 Japan
}

\begin{abstract}
The correlation between the severity of vibration syndrome and hand-tool operating time in chain saw workers has been studied. The total chain saw operating time was calculated by using the equation: chain saw operating hours/day $\times$ days/year $\times$ years, and 266 chain saw operators were classified into four groups $(0-2000 \mathrm{~h}, 2000-5000 \mathrm{~h}, 5000-8000 \mathrm{~h}$, over $8000 \mathrm{~h})$. Forty-six forestry workers not using chain saws were used as controls. The prevalence rates of symptoms were checked and statistically compared in each group.

In the group with under 2000 hours' experience, symptoms were generally confined to tingling, numbness, or pain; with 2000-5000 hours peripheral nerve and circulatory disturbances, including Raynaud's phenomenon, and muscle and general body conditions were influenced to some degree; with 5000-8000 hours' functional changes were noted; while with over 8000 hours about half the operators suffered severely from functional or organic changes due to vibration.
\end{abstract}

Since Loriga ${ }^{1}$ first reported the occurrence of occupational hazards due to the use of vibrating tools, many cases of workers affected by the use of vibrating tools in a wide range of industrial tasks (riveting, drilling, or jobs requiring chain saws and pneumatic hammers) have been reported. Many researchers first paid attention to vibration-induced white finger (Raynaud's phenomenon) and this syndrome is now well described. Recently, however, the concept of a "vibration syndrome" has been introduced to encompass the complex of symptoms associated with vibrating tools, such as vibration-induced white finger (Raynaud's phenomenon), hypesthesia of the hand and arm, weakness of grip strength, restriction of joints in hands, and so on. ${ }^{2-4}$

Several papers investigating the frequency and severity of vibration syndrome have been published, ${ }^{5-7}$ and criteria for the diagnosis of vibration syndrome have been established and used to describe the progress of this syndrome. ${ }^{6}$ These papers have detailed the progress of the syndrome but they do not show the correlation between the time for which vibrating tools have been used and each symptom, except Raynaud's phenomenon.

In this paper we have introduced "total operating time (TOT)" as a new index of vibration dose and have tried to show the correlation between the sev-

Received 28 September 1981

Accepted 18 February 1982 erity of vibration syndrome and total hand tool operating time by using the medical records of over 2000 chain saw workers. The field study was carried out from 1975 to 1979.

\section{Subjects}

Over 2000 forestry workers in the mountain area near Osaka in Japan were surveyed and examined for vibration syndrome. From these, 266 subjects professionally exposed to chain saw hand-arm vibration were selected; 46 controls, forestry workers never exposed to vibration, were also selected. We used these subjects who were all men and aged from 40 to 59 to eliminate the effects of sex and age.

To determine the vibration exposure dose for an individual, TOT was calculated from the full occupational history using the following equation: chain saw operating hours/day $\times$ days/year $\times$ years. If the vibration stimulus was constant in each work condition TOT might be considered to be a better parameter for the assessment of vibration exposure dose than saw-using years, because chain saw operating hours/day and operating days/year varied among the operators.

Subjects were classified into five groups according to TOT as follows; group A: 46 controls never exposed to vibration, group B: 39 operators with under 2000 hours' experience, group C: 76 operators with 2000-5000 hours' experience, group 
D: 51 operators with $5000-8000$ hours' experience, and group E: 100 operators with over 8000 hours' experience (table 1).

\section{Methods}

\section{SUBJECTIVE SYMPTOMS}

All subjects were interviewed by public health nurses to elicit subjective symptoms of vibration syndrome. These symptoms were numbness or tingling of the hands and arms, pain in the forearm and upper arm, and general symptoms due to physical and mental exhaustion (general fatigue, tiredness in the arms, pain in the back, vertigo, irritability, sleeplessness, and palmar sweating). The frequency and severity of the symptom were checked precisely.

Raynaud's phenomenon was identified by a doctor after a careful interview; the onset, duration, and recovery time of Raynaud's phenomenon, the pattern of attack in the fingers, the frequency in the different seasons, and the weather condition at the time of an attack were all determined.

\section{PERIPHERAL CIRCULATORY FUNCTION TESTS}

Finger skin temperature was measured before and after cold water immersion of the hand (10 $\mathrm{min}$ at $\left.10^{\circ} \mathrm{C}\right)$. Here we used the index of recovery rate given by the equation: skin temperature at 10 minutes after immersion/skin temperature before immersion $\times 100$, and the lower limit of normality was set at $45 \%$ assessed from examining healthy subjects.

Hyperaemia time of the nail was observed immediately after cold water immersion of the hand $\left(10 \mathrm{~min}\right.$ at $\left.10^{\circ} \mathrm{C}\right)$. Hyperaemia time is the recovery time of red colour of the whole area of the nail after nail pressure for 10 seconds produced by the tester's thumb and forefinger; it was measured with a stop watch. Over three seconds was judged to be a prolonged hyperaemia time.

SENSORY EXAMINATIONS OF HAND AND ARM The vibration sense threshold of the fingers was measured at $125 \mathrm{~Hz}$ with a vibration sensation meter (Rion AU-02; $0 \mathrm{~dB}$ ref $0.3 \mathrm{~m} / \mathrm{sec}^{2}$ ), whose output level could be changed from $-10 \mathrm{~dB}$ to 40 $\mathrm{dB}$. The subject put his finger tip on the oscillator and he responded by saying "buzzing" when he felt vibration. We regarded his minimum perceptible $\mathrm{dB}$ as the vibration sense threshold.

Pain sensitivity was examined by pricking the back of the finger tip with successively graded (1-10 g) weighted needles. Pain threshold was obtained by the minimum weight at which the subject felt pain. The upper limits of normality were evaluated to be $10 \mathrm{~dB}$ in vibration threshold measurement and $3 \mathrm{~g}$ in pain sensitivity test from the examination of healthy subjects. Hypesthesia of the hand and arm (light touch) was examined with a brush.

MOTOR FUNCTION TESTS OF HAND AND ARM

Muscle and joint pain in the hand and arm were examined. Mobility of the joints in the forearm and upper arm and muscle atrophy of the hand were also examined by palpation of the muscles and joints.

The muscle strength of hand-grip in both hands was measured by using a hand-grip dynamometer. The subjects were given five trials with each hand, and the highest measurement was adopted. Weakness of muscle strength was defined as a grip strength below $35 \mathrm{~kg}$.

To compare the severity of vibration syndrome with the TOT, the prevalence of subjective symptoms and abnormal findings at the time of the medical examination were checked and statistically compared in each group (groups $\mathrm{A}-\mathrm{E}$ ) by using $\chi^{2}$ or Student's $t$ test.

\section{Results}

\section{CIRCULATORY DISTURBANCES OF THE FINGER}

Raynaud's phenomenon, one of the most typical symptoms in vibration syndrome, was observed more often as the TOT increased. There were significant differences between groups $A$ and $C$, and between groups $C$ and $E(p<0.05)$. An increase in rate started at about 2000 hours with a pronounced increase over 8000 hours $(47.0 \%)$.

Numbness or tingling of the hand and arm occurred in $34.8 \%$ of subjects in group $\mathrm{A}$, but complaints

Table 1 Age and chain saw usage years of the subjects classified in five groups (A-E) by total operating time of chain saw (TOT)

\begin{tabular}{|c|c|c|c|c|}
\hline & Number & $\begin{array}{l}\text { TOT } \\
\text { (hours) }\end{array}$ & Chain saw usage years & Age \\
\hline $\begin{array}{l}\text { Group A } \\
\text { Group B } \\
\text { Group C } \\
\text { Group D } \\
\text { Group E }\end{array}$ & $\begin{array}{r}46 \\
39 \\
76 \\
51 \\
100\end{array}$ & $\begin{array}{l}0 \\
0-2000 \\
2000-5000 \\
5000-8000 \\
8000-\end{array}$ & $\begin{array}{r}0 \\
5.8 \pm 3.2 \\
8.6 \pm 3.5 \\
9.4 \pm 4.8 \\
12.6 \pm 5.5\end{array}$ & $\begin{array}{l}49.8 \pm 5.3 \\
47.9 \pm 8.9 \\
47.6 \pm 7.2 \\
45.4 \pm 11.7 \\
47.5 \pm 8.1\end{array}$ \\
\hline
\end{tabular}

$($ Mean \pm SD) 
increased to $84.0 \%$ in group $\mathrm{E}$. The prevalence rates rose significantly above 2000 hours.

A delayed recovery of finger skin temperature (below $45 \%$ ) was observed in $30.4 \%$ of subjects in group $A$, but the rates showed a rise to $48 \cdot 7-56.0 \%$ among groups $\mathrm{C}-\mathrm{E}$, the differences being significant at the $5 \%$ level.

The prevalence rates of prolonged reactive hyperaemia time of the nail (over 3 seconds) were higher in all groups as compared with controls $(p<$ 0.05 ) (fig 1).

The prevalence rates in operators with abnormal findings in both circulatory function tests were $27.6-35.0 \%$ in groups $\mathrm{C}-\mathrm{E}$ and showed a significant increase over 2000 hours. The prevalence of Raynaud's phenomenon accompanied with abnormal findings in these two tests also increased with an increase in TOT (fig 2). These results showed a strong correlation between the prevalence of Raynaud's phenomenon and the vibration exposure time.

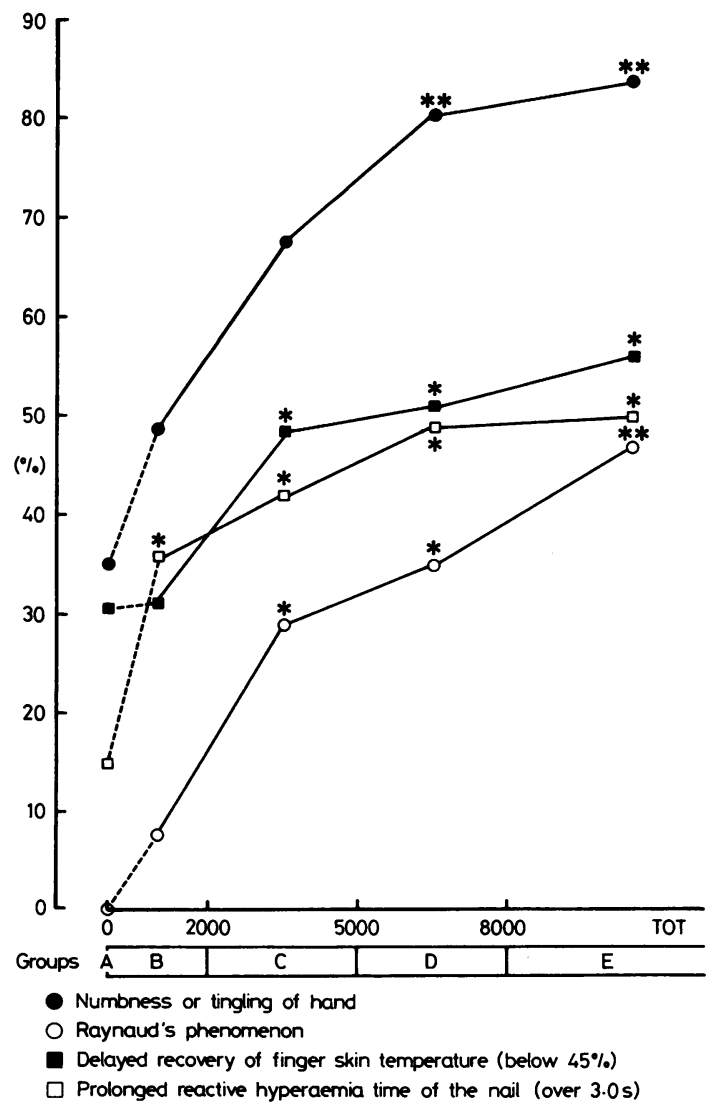

Fig 1 Prevalence rates of subjective symptoms and clinical fundings on circulatory disturbance of finger. *Significant difference as compared with group $A .{ }^{* *}$ Significant difference as compared with group $C(p<0.05)$.
SENSORY DISTURBANCES OF THE FINGER

The percentage of loss of vibratory sense (over 10 dB) rose significantly with TOT in all groups with over 2000 hours' experience, especially in the group over $\mathbf{8 0 0 0}$ hours as compared with the control group $(\mathrm{p}<0.05)$.

Loss of pain sense (over $3 \mathrm{~g}$ ) was observed more often in groups C-E than in groups A and B. A pronounced increase in the prevalence of loss of both vibratory sense and pain sense was found in all groups with over 2000 hours as compared with groups with under 2000 hours (fig 3).

Clinically manifest hypoesthesia of the hand and arm (light touch) was observed more frequently in all groups with over 2000 hours' experience.

\section{DAMAGE TO MUSCLES AND JOINTS}

Many operators subjectively complained of muscle and joint pain in the hands. The prevalence rates of pain in the hand, forearm, and shoulder were significantly higher with over 2000 hours' exposure $(p<0.05)$. Pain in the wrist, elbow joint, and upper arm increased at around 2000 hours and increased remarkably at over 5000 hours (fig 4).

Weakness of grip strength (below $35 \mathrm{~kg}$ in either hand) was observed in $23-28 \%$ of operators with over 2000 hours' experience.

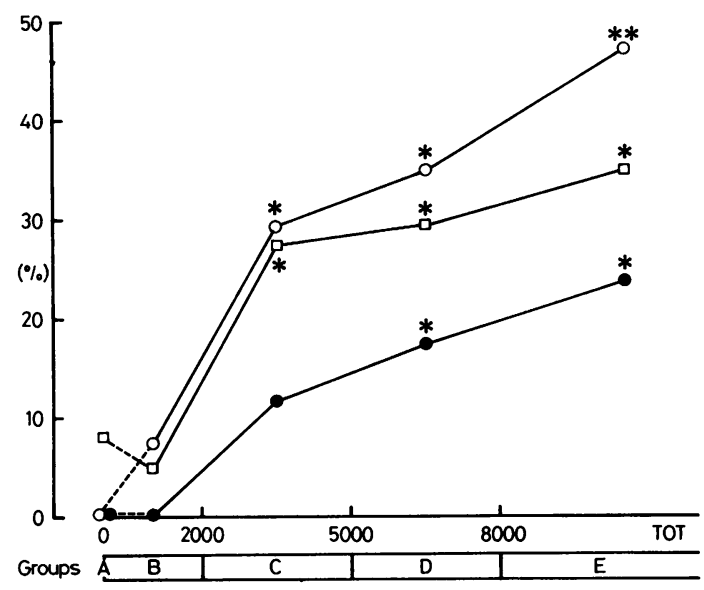

Raynaud's phenomen

$\square$ Delayed recovery of finger skin temperature with prolonged reactive hyperaemia time of nail

- Raynaud's phenomenon with delayed recovery of finger skin temperature and prolonged reactive hyperaemia time of nail

Fig 2 Prevalence rates of Raynaud's phenomenon and abnormal findings in both recovery rate of finger skin temperature and reactive hyperaemia time of the nail. *Significant difference as compared with group $A$. **Significant difference us compared with group $C(p<$ 0.05). 


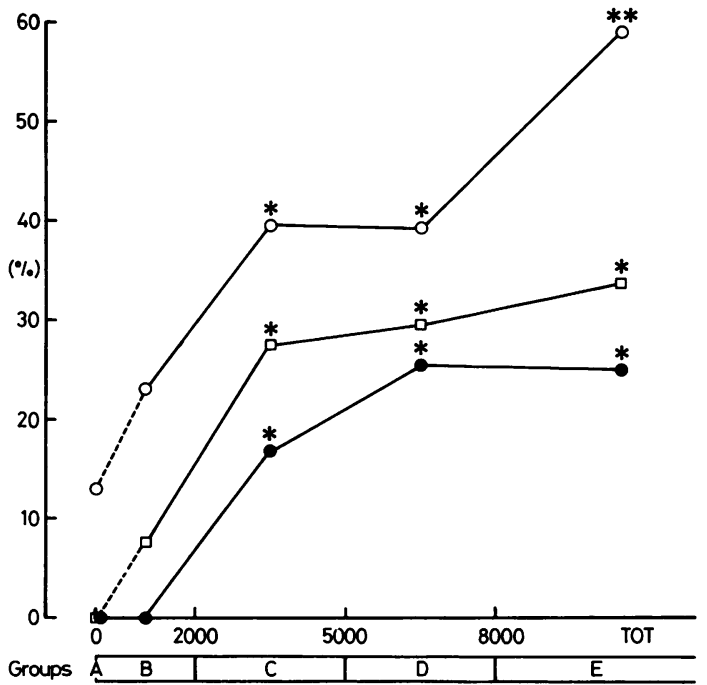

$O$ Loss of vibratory sense (over $10 \mathrm{~dB}$ at $125 \mathrm{~Hz}$ )

$\square$ Loss of pain (over $3.0 \mathrm{~g}$ )

- Loss of both vibratory and pain sense

Fig 3 Prevalence rates of loss of vibratory sense and loss of pain sense or both. *Significant difference as compared with group $A .{ }^{*}$ *Significant difference as compared with group $C$ $(p<0.05)$.

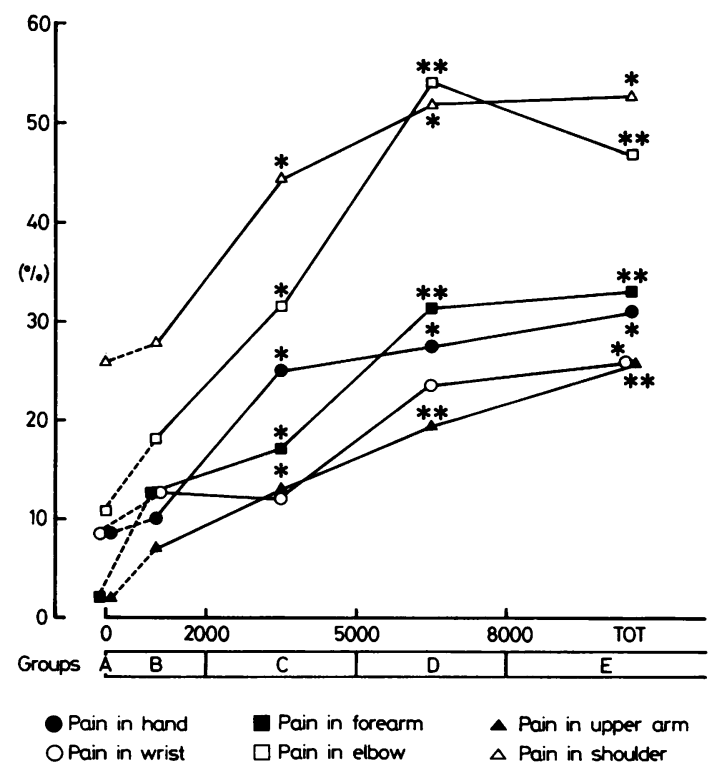

Fig 4 Prevalence rates of pain in muscles and joints of hand and arm. *Significant difference as compared with group $A .{ }^{* *}$ Significant difference as compared with group $C$ $(p<0.05)$.
Atrophy of the muscles of the hand or restriction of joint-mobility in the hands are not so common among chain saw operators, but these signs are important as indicative organic changes due to the use of vibrating tools. The prevalence rate of muscle atrophy, commonly observed in the dorsal interosseous muscles, showed a gradual rise to $7.0 \%$ in groups with over 8000 hours' exposure.

Disturbance of mobility over one-third of the range of motion at the elbow joint (more commonly observed than in other joints) occurred in about $10 \%$ of subjects in groups $B$ and C, $16-18 \%$ in groups $\mathrm{D}$ and $\mathrm{E}$, and in about $9 \%$ of the control group.

\section{GENERAL SYMPTOMS DUE TO PHYSICAL AND} MENTAL EXHAUSTION

The prevalence rates of subjective symptoms of general fatigue, tiredness in the arms and pain in the back were $37.0 \%, 21.7 \%$, and $6.5 \%$ respectively even in group $\mathrm{A}$, but showed a gradual rise to $73.0 \%, 63.0 \%$, and $53.0 \%$ in group E. These prevalence rates became significantly higher with an increase of TOT, especially in group $\mathrm{E}$ as compared with groups $A$ and $C(p<0.05)$.

The prevalence rates of vertigo, irritability, sleeplessness, or palmar sweating, considered to be autonomic nerve disturbances due to the stress of vibration, cold weather, or noise are shown in fig 5. The prevalence rates of these symptoms were significantly higher at over 5000 or 8000 hours as compared with the control group $(p<0.05)$.

The results obtained in this study according to total operating time (TOT) are summarised in fig 6.

In the group operating the chain saw for under 2000 hours the symptomatology was generally

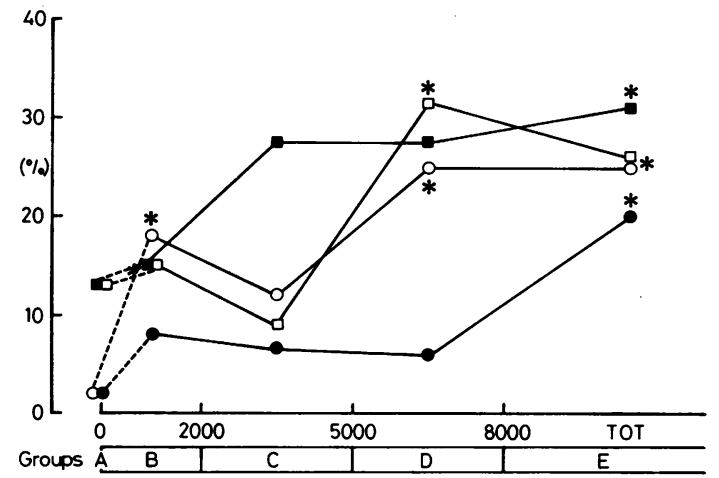

$$
\text { - Vertigo Sleeplessness }
$$$$
\text { O Irritability } \quad \square \text { Palmar sweating }
$$

Fig 5 Prevalence rates of symptoms due to autonomic nerve disorder. *Significant difference as compared with group A $(p<0.05)$. 
confined to tingling, numbness, or pain and there was an area of overlap between this vibrationexposed group and the controls.

In the group with experience ranging from 2000 to 5000 hours not only the peripheral circulation and the peripheral nerves but also the muscles and general wellbeing were influenced to some degree. The prevalence rate of Raynaud's phenomenon reached about $30 \%$. Delayed recovery rate of finger skin temperature or prolonged reactive hyperaemia time, or both, were also observed more frequently. On the other hand, peripheral nerve disturbances became manifest as clinical findings of loss of either vibratory or pain sense, or both, or hyperaesthesia of the hand. Weakness of grip strength also appeared in this group.

A longer operating time of 5000-8000 hours may be defined as a progressive stage compared with that of 2000-5000 hours. In this group Raynaud's phenomenon increased in frequency and severity. Both circulatory and nerve functions were observed to deteriorate in repeated objective examination and the prevalence of muscle disturbances, pain in joints, and others was increased. Most symptoms in this group were considered to be functional changes, but in some cases there were organic changes-for example, limitation of movement in the elbow or shoulder joints or atrophy in the muscles of the hand.

In the group with an operating time of over $\mathbf{8 0 0 0}$ hours, about half the operators suffered from functional or organic changes due to vibration, and with the increase in the time of vibration exposure almost all the operators would be expected to be affected to some degree. Raynaud's phenomenon was observed in about half the operators; whiteness of the finger extended to the base of the finger in this group

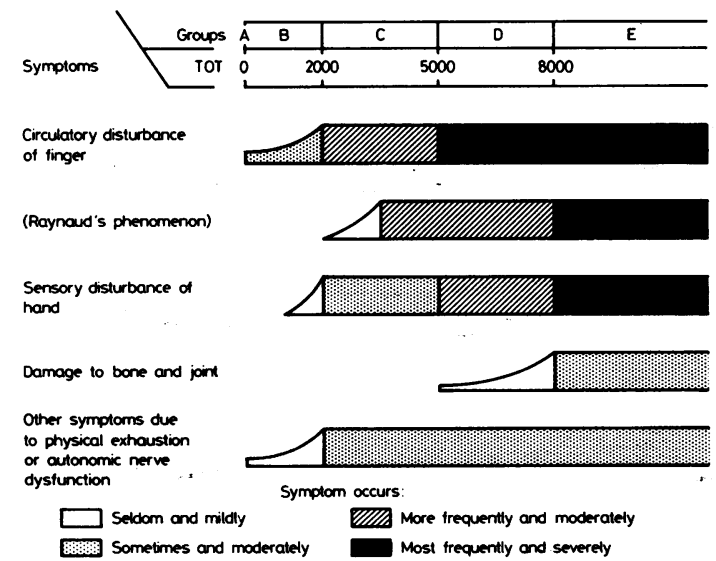

Fig 6 Frequency and severity of each symptom by TOT. whereas it was generally confined to the finger tip in the first group. In this group circulatory disturbances and disturbances of neurological function progressed in severity to become typical of the pathological condition in vibration syndrome, occasionally combined with damage to the bones and joints. Severe effects of the autonomic nervous system were recognised in this group.

\section{Discussion}

It is generally accepted that the vibration syndrome indicates disease of the bones, joints, muscles, blood vessels, or nerves of the hand, arm, or shoulder and includes Raynaud's phenomenon caused by vibrating machines. ${ }^{2-4}$

From the results of our study on the vibration syndrome it seems that symptoms can be divided into four categories; (1) circulatory disturbances of the fingers, including Raynaud's phenomenon, (2) sensory disturbances of the hand, (3) damage to the muscles and joints, and (4) mental and physical exhaustion or autonomic nerve dysfunction. Pyykkö et $a^{8}$ make a similar classification.

The progression of each symptom in response to vibration exposure time, however, has not been fully understood. Here, we will discuss the correlation between symptoms and TOT in chain saw operators.

Firstly, we must consider the level of chain saw vibration as a dose. In Japan the chain saw that is in common use has an acceleration level ranging from $124-146 \mathrm{~dB}\left(0 \mathrm{~dB}\right.$ ref $\left.10^{-5} \mathrm{~m} / \mathrm{sec}^{2}\right)$ as measured by all pass filter measurement. We regarded the vibration level as almost constant at any work condition and used TOT as a whole vibration dose to the body in this study.

With under 2000 hours' exposure, the operator may be considered to be in the "latent interval" of the vibration syndrome. The vibration at this stage affects both the peripheral circulation and peripheral nervous system, but any changes are usually subclinical.

Further constant exposure to vibration may give rise to repeated vasospasm of capillaries and reduced blood flow in the fingers and peripheral nervous system. Clinically, low skin temperature in the fingers and loss of vibratory or touch sense appears in response to 2000-5000 hours' experience. These symptoms occur more often with the increase of TOT. They are important as a precursor of Raynaud's phenomenon when they occur more frequently and severely.

The prevalence rate of Raynaud's phenomenon starts to increase at about 2000 hours $(7.7 \%)$ with a pronounced increase over 8000 hours $(47.0 \%)$. If an operator uses a chain saw for four hours a day 
and 150 days a year, the operator may begin to suffer from Raynaud's phenomenon in three or four years. Turtiainen' found results similar to ours. Numbness of the hand and Raynaud's phenomenon appeared after 2.2 years' use of the saw and in those who sawed continually for six to 14 years $(2 \cdot 8$ hours a day, 22.3 days a month, which is calculated to be from about 5000 to 10500 hours in TOT), the prevalence of Raynaud's phenomenon was roughly $50 \%$. Pyykkö $\ddot{B}^{5}$ calculated that the average latency of Raynaud's phenomenon was $5600 \pm 2500$ hours, which was longer than ours. Continuous long-term vibration exposure may cause disorders of the peripheral circulation such as damage to the peripheral nerve ${ }^{10}$ disturbance of cold-induced vasodilatation, ${ }^{11}$ thickening of the capillary wall, ${ }^{12}$ or a combination of these, so that Raynaud's phenomenon occurs more frequently and severely with strong response to TOT.

Muscle is more easily affected than bone by vibration and weakness of grip strength is a well-known clinical sign. ${ }^{713}$ This is supported by our serological study. We have examined not only grip strength but also the activities of the sarcoplasmic enzymes of muscle in a field study'; these include aldolase (ALD), creatine phosphokinase (CPK), and lactic dehydrogenase (LDH). Table 2 shows the mean values and the standard deviation of the activities of these three enzymes in serum and the grip strength by groups related to TOT. The activities of aldolase, creatine phosphokinase, and lactic dehydrogenase showed a tendency to increase with saw usage time, while grip strength showed the opposite trend. There was a significant difference in the activities of creatine phosphokinase and lactic dehydrogenase between the control group and each operator group and, in aldolase, between the control and each group with more than 5000 hours' experience. We suspected that high activities of sarcoplasmic enzymes might be due to increased cellular permeability of the muscular system affected by vibration. Weakness of grip strength was observed even after a short period of experience below 2000 hours, but atrophy of the muscles of the hand was seldom observed even after more than 8000 hours $(7 \%)$.

Damage to the bones in the arms has been observed as pain on movement or restriction of movement in the wrist, elbow, and shoulder joints. The changes induced by the chain saw occur no more often than those caused by reciprocating or rotating vibrating tools such as rock drills or riveting hammers. ${ }^{14}$ is The prevalence rate of restriction of movement in the elbow joint in this study was 15$18 \%$ even after more than 5000 or 8000 hours' experience. Damage to muscle and bone may be defined as "late symptoms in vibration syndrome" and is the result of the accumulated effects of vibration to the arms. With longer-term exposure to vibration of 5000 or 8000 hours or more, the number of operators with an advanced stage of such organic changes, as well as functional changes, increases.

As to the effects of vibration on the autonomic nervous sytem, there are many opinions. To evaluate objectively the effects of vibration or other circumstances during stress, we paid attention to the hormones secreted by the adrenal medulla in our previous study. Table 3 shows the values of catecholamines (adrenaline and noradrenaline)

Table 2 Grip strength and sarcoplasmic enzymes by groups in accordance with TOT

\begin{tabular}{|c|c|c|c|c|c|}
\hline \multirow{2}{*}{$\begin{array}{l}\text { TOT } \\
\text { (hours) }\end{array}$} & \multirow[t]{2}{*}{ No } & \multirow{2}{*}{$\begin{array}{l}\text { Grip strength } \\
(k g)\end{array}$} & \multicolumn{3}{|c|}{ Sarcoplasmic enzymes } \\
\hline & & & $A L D(U)$ & $C P K(U)$ & $L D H(U)$ \\
\hline $\begin{array}{l}\text { Controls } \\
0-2500 \\
2500-5000 \\
5000-7500 \\
7500-\end{array}$ & $\begin{array}{l}36 \\
28 \\
40 \\
25 \\
41\end{array}$ & $\begin{array}{l}52 \cdot 5 \pm 6.9 \\
46 \cdot 5 \pm 9 \cdot 1^{*} \\
43.6 \pm 9.6^{*} \\
41.8 \pm 7 \cdot 5^{*} \\
40.1 \pm 9.9^{*}\end{array}$ & $\begin{array}{l}3 \cdot 3 \pm 1 \cdot 0 \\
3 \cdot 5 \pm 1 \cdot 0 \\
3 \cdot 8 \pm 1 \cdot 5 \\
4 \cdot 0 \pm 1 \cdot 5^{*} \\
4 \cdot 3 \pm 1 \cdot 7^{*}\end{array}$ & $\begin{array}{l}58.2 \pm 14.4 \\
71.7 \pm 25.6^{*} \\
70.2 \pm 23.4^{*} \\
75.2 \pm 34.5^{*} \\
69.6 \pm 29.9^{*}\end{array}$ & $\begin{array}{l}287 \pm 51 \\
331 \pm 47^{*} \\
324 \pm 79^{*} \\
339 \pm 63^{*} \\
324 \pm 60^{*}\end{array}$ \\
\hline
\end{tabular}

*Significant difference as compared with controls at $5 \%$ level.

$($ Mean $\pm \mathrm{SD})$

Table 3 Concentrations of urinary catecholamines by groups in accordance with TOT

\begin{tabular}{lllll}
\hline $\begin{array}{l}\text { TOT } \\
\text { (hours) }\end{array}$ & Number & $\begin{array}{l}\text { Age } \\
\text { (year) }\end{array}$ & $\begin{array}{l}\text { Adrenaline } \\
\text { (ng/mg creatinine) }\end{array}$ & $\begin{array}{l}\text { Noradrenaline } \\
\text { (ng/mg creatinine) }\end{array}$ \\
\hline Controls & 21 & $39 \cdot 2 \pm 10 \cdot 2$ & $7 \cdot 9 \pm 3 \cdot 3$ & $33 \cdot 9 \pm 11 \cdot 3$ \\
$0-4000$ & 27 & $48 \cdot 0 \pm 5 \cdot 9$ & $20 \cdot 6 \pm 9 \cdot 9^{* *}$ & $40 \cdot 5 \pm 11 \cdot 9$ \\
$4000-8000$ & 30 & $47 \cdot 4 \pm 7 \cdot 5$ & $21 \cdot 1 \pm 15^{* *}$ & $45^{*}+3 \pm 23 \cdot 1^{*}$ \\
$8000-12000$ & 20 & $45 \cdot 6 \pm 7 \cdot 0$ & $21 \cdot 3 \pm 10 \cdot 2^{* *}$ & $43 \cdot 8 \pm 16 \cdot 4^{*}$ \\
$12000-$ & 21 & $45 \cdot 5 \pm 5 \cdot 1$ & $21 \cdot 2 \pm 13 \cdot 7^{* *}$ & $45 \cdot 2 \pm 14 \cdot 7^{*}$ \\
\hline
\end{tabular}

*Significant difference as compared with controls at $5 \%$ level, ${ }^{* *}$ at $0.5 \%$ level. 
excreted in the urine at noon hour by groups in accordance with TOT. There was a significant difference in the urinary excretion of catecholamines between each operator group and the control group $(p<0.05)$, suggesting that increased adrenal activity may result from the use of chain saws. Makarenko ${ }^{16}$ also reported the rise of noradrenaline in the urine in patients with vibration syndrome, but there are some papers showing that the values of noradrenaline were lower in patients than in controls. ${ }^{17} 18$ Our results suggest that the autonomic nervous sytem in operators would be influenced by a short experience of vibration, but there is no further response with increased usage time nor with the prevalence of subjective symptoms.

Some results of this study were presented at the 3rd International Symposium on Hand-Arm Vibration, Ottawa, 1981.

\section{References}

' Loriga G. Il lavro coi martelli pneumatici. Boll Inspett Lavoro 1911;2:35.

${ }^{2}$ Taylor W, Pearson J, Kell RL, Keighley GD. Vibration syndrome in forestry commission chain saw operators. $\mathrm{Br} \mathrm{J}$ Ind Med 1971;28:83-9.

${ }^{3}$ McCallum RI. Vibration syndrome. Br J Ind Med 1971;28:90-3.

4 Taylor W. Vibration syndrome: introduction. In: Taylor W, ed. The vibration syndrome. London: Academic Press, 1974:1-12.
${ }^{5}$ Pyykkö I. The prevalence and symptoms of traumatic vasospastic disease among lumberjacks in Finland. Work Environ Health 1974;11:118-31.

- Taylor W, Pelmear PL, Pearson J. Raynaud's phenomenon in forestry chain saw operators. In: Taylor $\mathrm{W}$, ed. The vibration syndrome. London: Academic Press, 1974:121-39.

' Kasamatsu T, Miyashita K, Shiomi S, Itoh N, Iwata H. Relationships among sarcoplasmic enzymes in serum, muscular strength and subjective symptoms. Wakayama Medical Reports 1979;22:95-102.

${ }^{8}$ Pyykkö I, Korhonen O, Sairanen E, Färkkilä M, Starck J. Vibration syndrome among forest workers in Finland. In: Proceedings of Third International Symposium on Hand-Arm Vibration. Ottawa. (in press).

9 Turtiainen K. Chain saw operator's opinions of chain saw vibration. Work Environ Health 1974;11:132-5.

${ }^{10}$ Marshall J, Poole EW, Reynard WA. Raynaud's phenomenon due to vibrating tools. Lancet 1954 ; i:1151-6.

"Magos L, Okas G. Cold dilatation and Raynaud's phenomenon. Arch Environ Health 1963;7:402-10.

${ }^{12}$ Ashe WF, Cook WT, Old JW. Raynaud's phenomenon of occupational origin. Arch Environ Health 1962;5:333-43.

${ }^{13}$ Färkkilä M, Pyykkö I, Korhonen O, Stark J. Vibration-induced decrease in the muscle force in lumberjacks. Eur J Appl Physiol 1980;43:1-9.

${ }^{14}$ Hagen J. Erkrankungen durch Pressluft-Werkzeugarbeit. Leipzig: Johann Ambrosius Barth, 1947.

${ }^{15}$ Iwata $\mathrm{H}$. Effects of rock drills on operators. Part 3 Joint and muscle pain and deformity of bone and joint. Ind Health 1968;6:47-58.

${ }^{16}$ Makarenko NA. State of the sympathoadrenal system in patients with vibration disease. Brachevnoe Dero 1968;1:94-7.

17 Vein AM, Matlina ES, Muradkhanov MA. Sympatho-adrenal system in patients with vibration disease. Gigiena Tyruda 1971;15:12-6.

${ }^{18}$ Krasavina TS, Volkova TN, Gornik VM. Functional condition of the sympathoadrenal system in patients with late stage of vibration disease. Klin Med 1977;55:77-80.

\section{Notice}

21st International Congress on Occupational Health. Dublin, 9-14 September 1984.

The Twenty-first International Congress on Occupational Health will take place in Dublin from 9 to 14 September 1984. For details of the Congress please contact: Dr C S Macnamara. Organising Secretary. XXI International Congress on Occupational Health, 44 Northumberland Road, Dublin 4, Eire. 